\title{
The Manufacture of Lightweight Aggregates from Recycled Masonry Rubble
}

\author{
Anette Mueller ${ }^{1}$, Steffen Liebezeit ${ }^{1}$, Barbara Leydolph ${ }^{1}$, Ulrich Palzer ${ }^{1}$ \\ ${ }^{1} \mathrm{IAB}$ - Institut für Angewandte Bauforschung Weimar gGmb \\ Über der Nonnenwiese 1, 99428 Weimar, Germany, Phone (+49) 3643 8684-162; \\ E-mail: a.mueller@iab-weimar.de
}

\begin{abstract}
At present, heterogeneous and fine-grained masonry rubble can only be recycled at very low level. To overcome this limitation, the material was employed as feedstock for the production of lightweight aggregates in a thermal process similar to that used in the manufacture of expanded clay and expanded slate. To that end, the fundamental suitability of masonry rubble as a raw material was evaluated. Experiments were carried out which indicated that lightweight granules with defined, adjustable properties similar to those of natural-materialbased aggregates could be manufactured from masonry rubble. Structural lightweight concretes produced with these secondary aggregates achieved comparable performance to lightweight concretes produced with conventional expanded clay. Lightweight recycled building material aggregates represent a product that hardly requires any primary resources in its manufacture.
\end{abstract}

Keywords: Masonry rubble, feedstock recycling, expansion process, rotary kiln, lightweight aggregate.

\section{Characterization of masonry rubble}

At present, the mix of various wall construction materials, mortar, plaster, and further components that make up masonry rubble cannot be adequately utilized. This results from the considerable heterogeneity of the material composition and the large proportion of fines. In the future, strict closed-loop recycling laws and limited landfill capacity will prevent the disposal or application of these materials as fill or in the construction of landfills. In this context, a new technology for the manufacture of lightweight aggregates from masonry rubble was developed. These lightweight construction aggregates are produced from mineral construction waste and can be employed in the manufacture of lightweight mortars and concretes.

Masonry rubble consists of multiple components. As well as brick, other construction materials present can include calcium-silicate brick, aerated autoclaved concrete, precast concrete, or natural stone. Additional components can include lime mortar, lime cement mortar, cement mortar, interior gypsum plasters, exterior plasters, insulation, tiles, and façade panels. Recycled aggregates manufactured from this material through comminution and screening can vary greatly in their composition. This has been confirmed by the results of sorting analyses of processed masonry rubble (Figure 1). The brick and other ceramic material content vary between a minimum and a maximum of 24 and 92 mass-\% respectively, with a mean value of 50 mass- $\%$. Concrete and mortar are the second most dominant material group. The mean is 46 mass- $\%$ with a range between 8 and 70 mass- $\%$.

Within a batch of material there may be a variety of building materials with greatly differing properties. This diversity of materials is reflected by the range of the particle density. Even 
when materials with a particle density less than $1700 \mathrm{~kg} / \mathrm{m}^{3}$ are omitted, the range of the densities is $750 \mathrm{~kg} / \mathrm{m}^{3}$.

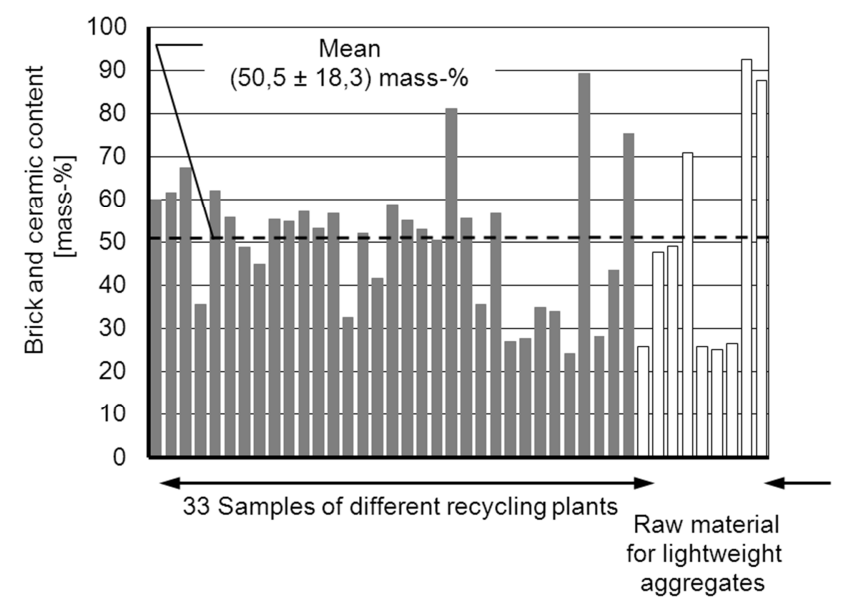

Figure 1. Brick content of 42 masonry samples taken from processed masonry rubble piles at various stationary recycling plants including the raw materials used in the experiments

For the recovery of masonry rubble as feedstock for the production of lightweight aggregates in a thermal process similar to that used in the manufacture of expanded clay and expanded slate the composition of masonry rubble is particularly relevant. In order to make an initial assessment, the oxide composition of masonry in the ternary system $\mathrm{SiO}_{2}-\mathrm{Al}_{2} \mathrm{O}_{3}$-flux $\left(\mathrm{CaO}+\mathrm{MgO}+\mathrm{Fe}_{2} \mathrm{O}_{3}+\mathrm{Na}_{2} \mathrm{O}+\mathrm{K}_{2} \mathrm{O}\right)$ is recorded (Figure 2). This system is used to assess raw materials for ceramic building materials, including those for the manufacture of expanded clay according to $[1,2]$. With few exceptions, the composition of 46 samples of masonry rubble analyzed fell into the marked area suitable for expanded clay production according to the literature. Thus, the reuse of masonry rubble using technology similar to that for expanded clay production is an alternative worth considering.

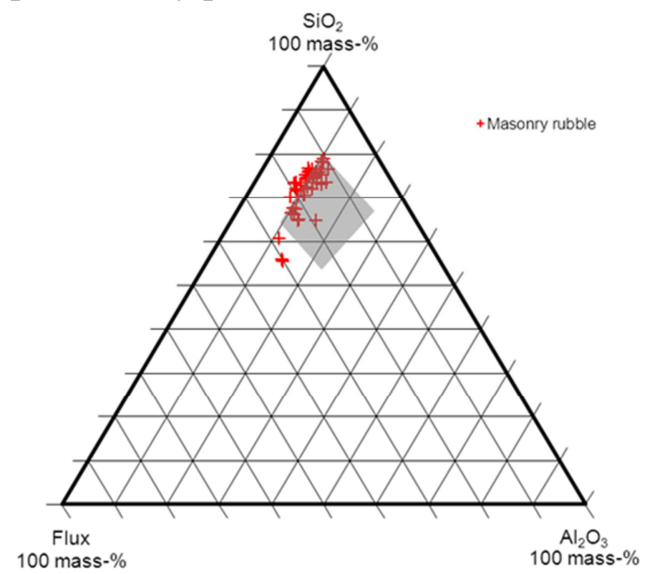

Figure 2. Relative positions of real masonry rubble in the ternary system $\mathrm{SiO}_{2}-\mathrm{Al}_{2} \mathrm{O}_{3}$-Flux $\left(\mathrm{CaO}+\mathrm{MgO}+\mathrm{Fe}_{2} \mathrm{O}_{3}+\mathrm{Na}_{2} \mathrm{O}+\mathrm{K}_{2} \mathrm{O}\right)$

Gray area: Area to be preferred for expanded clays $[1,2]$

\section{Conditions of manufacture of lightweight aggregates}

First, the conditions for manufacturing the lightweight aggregates and the influence of the composition of the masonry rubble were experimentally investigated. For that purpose, masonry rubble with a brick content of 48 mass-\% (approximately the mean value given in Figure 1) was crushed, ground, doped, and granulated in a pelletier mixer. Subsequent the green granules are stabilised and at the same time expanded by a thermal treatment in a laboratory rotary kiln (Figure 3). The influence of the firing temperature, the amount of added expanding agent and the brick content on the particle density and the single grain strength 
were investigated. Following preliminary analysis, silicon carbide $(\mathrm{SiC})$ was selected as the anding agent.
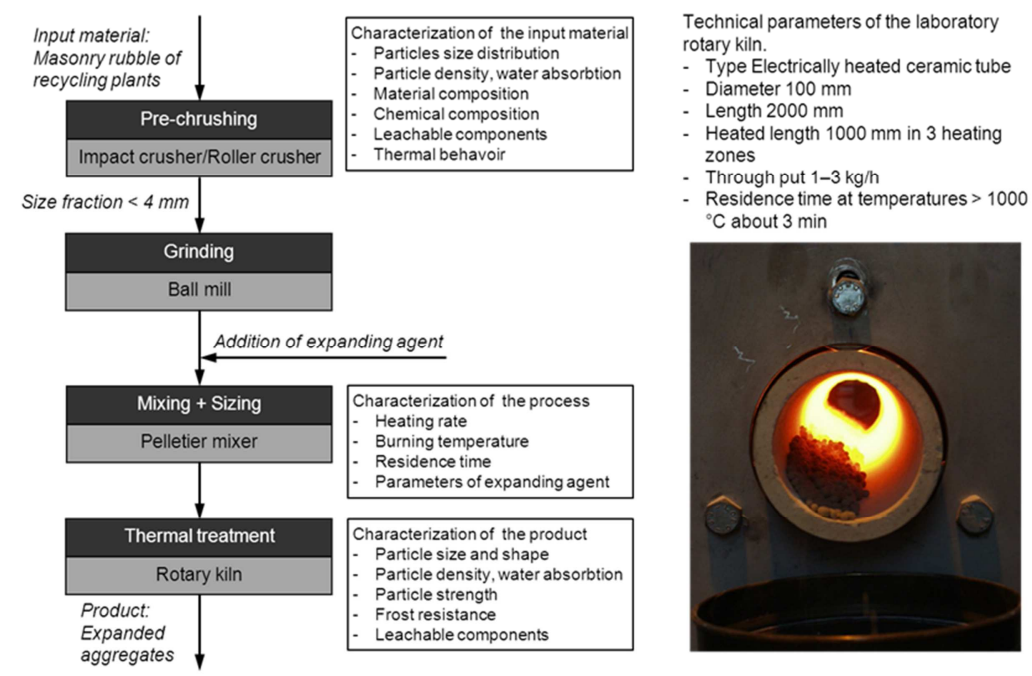

Figure 3. Experimental procedure for the manufacture of lightweight aggregates from masonry rubble in laboratory scale

As the results in Figure 4 show, increased firing temperature results in a reduction in particle density of the lightweight aggregates. Grain strengths for all of the granules follow a maximum function, whereby the maximum value was achieved with a firing temperature of $1120{ }^{\circ} \mathrm{C}$. The lowest density $\left(1000 \mathrm{~kg} / \mathrm{m}^{3}\right)$ was achieved at firing temperatures of $1160{ }^{\circ} \mathrm{C}$. At burning temperatures higher than $1200^{\circ} \mathrm{C}$ the granules began to melt and the grains adhered to each other. The influence of the silicon carbide content on the expansion process was analysed for a firing temperature of $1180{ }^{\circ} \mathrm{C}$. Green granules with differing $\mathrm{SiC}$ content were fired either once or twice in the rotary kiln. Double-firing is intended to extend the exposure time at a firing temperature. The density of granulate subject to a single firing indicates that values below $800 \mathrm{~kg} / \mathrm{m}^{3}$ are already possible with a SiC content of 1 mass-\%, which doesn't change much after a second firing. Dosing with 3 mass-\% reduces the density further if the material is fired a second time. Densities at or even below $600 \mathrm{~kg} / \mathrm{m}^{3}$ are achievable. Thus, the exposure time in the oven must be adjusted to correspond with the $\mathrm{SiC}$ dosing.
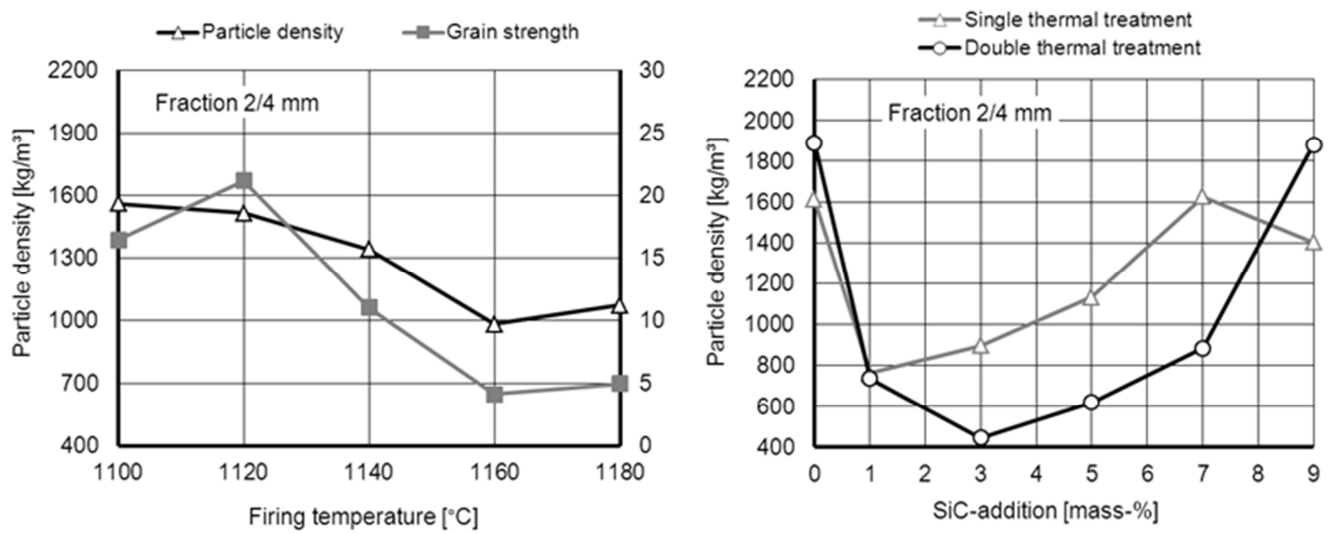

Figure 4 left. Influence of the firing temperature on the particle density and the grain strength of expanded granules.

Figure 4 right. Influence of $\mathrm{SiC}$-dosage on the particle density of expanded granules fired at a temperature of $1180^{\circ} \mathrm{C}$ 
Input material: Masonry rubble with 48 mass-\% clay brick, dosed with 3 mass-\% SiC

The influence of the brick content of the masonry rubble on the density of the lightweight aggregate was tested. Even 20 mass\% brick content allows aggregate with a density below $1000 \mathrm{~kg} / \mathrm{m}^{3}$ to be manufactured under laboratory firing conditions. The lowest densities were achieved with brick contents between 40 and 70 mass\%. It appears that densities increase above 70 mass\%. Overall, the aggregate seems to be relatively robust in relation to fluctuations in the brick content of the initial material.

\section{Conclusion: potential as resource-free aggregate}

The properties of the produced lightweight aggregates were compared to those of naturalmaterial-based aggregates. Structural lightweight concretes produced with these secondary aggregates achieved comparable performance to lightweight concretes produced with conventional expanded clay [3]. These promising results gave the impetus for initial technological considerations. The manufacture of the lightweight aggregates can be accomplished using expanded clay production technology. It begins with the treatment of masonry rubble, similarly to the process used in the recycling industry. The material is then stockpiled, and can be homogenized at the same time. Manufacture of the aggregates themselves begins with the grinding with the simultaneous addition of the expanding agent. Then the powdered masonry rubble is granulated. Experiments show that pelletizing mixers, pelleting presses, and pelletizing disk are suitable. Thermal stabilisation and expanding in a rotary kiln follows. In the subsequent cooler, the heat of the granulates is used to preheat the combustion air. An application of an inert release agent is necessary. After leaving the cooler the expanded granules are graded to recover the release agent at least partially.

In terms of consumption of primary resources, manufactured lightweight aggregates from masonry rubble presents a nearly "primary resource free" product. Only the expanding agent and the release agent, which is partially consumed in the thermal process, need to be added. Silicon carbide, which is otherwise a waste product of sanding and cutting processes, could be employed as an expanding agent. The manufacture of conventional expanded clay serves as a reference for considering the energy consumption of the recycled material. Like the process described here, production is divided into the following steps: coarse crushing of the raw material, grinding, and granulation, followed by thermal treatment in a rotary kiln. Assuming that the 'cold' process steps don't differ in their energy demand, the thermal processes can be considered in terms of energy savings and additional energy requirements. The energy savings arise from the fact that the masonry rubble-derived material requires a lower water content for shapening than clay. In addition, the energy demand associated with the dehydroxylation of the clay minerals can be saved, since this process has already taken place as part of the original brick manufacturing process. An additional energy consumption can result from calcium carbonate decomposition, if carbonised components from mortars and concretes are included in the masonry rubble. An initial assessment indicates that energy savings of approximately $15 \%$ are possible, taking calcium carbonate decomposition into account.

Various analyses indicate that an increase in gypsum content in demolition debris will need to be taken into account in the future [4]. As a result, sulfate reduction through mechanical detachment of gypsum plaster during demolition or in the course of processing is insufficient [5]. The manufacture of aggregates from recycled material could be used to effectively decrease the sulfate content in demolition waste, since gypsum can be thermally decomposed and subsequently recovered from the flue gas. 


\section{Acknowledgement}

The research project "Aufbaukörnungen" was sponsored by the Federal Ministry of Education and Research BMBF within the framework of the " $\mathrm{r}^{2}$ - Innovative Techno-logy for Resource Efficiency - Resource Intensive Production Processes" funding priority. Partners engaged in the joint project are listed on r-zwei-innovation.de.

\section{References}

[1] Riley, Ch.M. Relation of Chemical Properties to the Bloating of Clays. Journal of Am. Ceram. Soc. Vol. 34 (1951), pp 123-128.

[2] Wilson, H.: Lightweight Aggregates for the Construction Industry. Journal of Can. Ceram. Soc. Vol. 22 (1953), pp 44-50.

[3] Mueller, A.; Schnell, A.; Ruebner, C.: The manufacture of lightweight aggregates from recycled masonry rubble. Construction and Building Materials 98 (2015) 376-387.

[4] Arendt, M.: Kreislaufwirtschaft im Baubereich: Steuerung zukünftiger Stoff-ströme am Beispiel Gips. Dissertation, Karlsruhe 2000.

[5] Mueller, A.; Kehr, K.; Schnellert, T.: Gypsum under control. Gips Zeitschrift AT Mineral Processing - Aufbereitungstechnik für Mineralische Stoffe (English Edition), Volume 51, S. 28-43. 